\title{
Improving access to safe delivery for poor women by voucher scheme in Bangladesh
}

\author{
Akkur Chandra Das
}

Master(s) of Population Sciences (MPS) Scholar, Department of Population Sciences, University of Dhaka, Dhaka, Bangladesh.

\begin{abstract}
Maternal and child mortality are still higher in Bangladesh where delivery care services are associated with a number of problems. Demand-side financing, popularly well-known as maternal health care voucher, is found to reduce the financial barriers, increases choice for clients, and improves efficiency in delivery and quality of services which ultimately enhances maternal health. A cross-sectional study was conducted in different upzilas of Bhola district in Bangladesh among poor married women and found that voucher scheme receivers were 17.64 times more likely to receive delivery care services than respondents who were not part of the voucher scheme. On the other hand, the study pointed out that recipients of the voucher scheme received comparatively higher levels of delivery care services compared to those not in the voucher scheme, such as skilled birth attendance $(64.2 \%$ vs. $26.3 \%)$, institutional delivery services $(86.9 \%$ vs. $24.7 \%)$, and transport costs $(92.5 \%$ vs. $23.1 \%)$. As the voucher scheme receivers' delivery care services ensured better health status and care services than non-voucher scheme receivers in Bangladesh, the current study suggests that increasing the accessibility of voucher scheme programs will facilitate the provision of effective maternal health care services.
\end{abstract}

Keywords: Voucher scheme, Delivery care services, Demand-side financing, Maternal \& child health, Bangladesh.

\section{Introduction}

Maternal and child mortality are among the most important goals of the Millennium Development Goals (MDGs) and major concerns for policy makers in developing countries of the world like Bangladesh. Although Bangladesh has already achieved a remarkable success in reducing maternal and child death, then still in rural Bangladesh, around $71 \%$ of births take place at home where home delivery is preferred as it is associated with low cost so that delivery care services become low and resulted many complications which are the reasons of maternal and child mortality. ${ }^{1}$ This grim picture renders Bangladesh to greater misery along with other Asian developing countries. ${ }^{2}$ Financial barriers are one of the major indicators identified that lowered the delivery care services among the poorest women and also indicates that financial ability and protection are needed for the poorest to encourage the use of facilities for delivery and to prevent families from impoverishment. ${ }^{3}$ As a result, a program was introduced, namely demand-side financing (DSF), but also known popularly as the maternal health voucher scheme for low-income (poor) pregnant women. ${ }^{5}$ The aim of the program was to enhance the utilization of child and maternal health services and to remove financial barriers as a step towards improving maternal and children's health. The program is predominantly focused on $\mathrm{MDGs}^{4}$ with implementation and evaluation of multisectoral interventions to improve the access and quality of care for women who are poor, less-educated and live in rural areas in the post-MDG health and development agenda for achieving universal health coverage as there is considerable potential for improvement among these groups. ${ }^{5}$

\section{Practice Points}

- Maternal and child mortality are global public health concerns.

- The study revealed that the voucher scheme improves access to safe delivery for poor women and is intended to reduce financial barriers, increase the choice for clients, and increase efficiency in delivery and quality of services.

- Skilled birth attendance, institutional delivery services and the proportion of transport costs received by voucher scheme participants were higher than non-voucher scheme participants.

- Voucher scheme receivers were 17.64 times more likely to receive delivery care services than non-voucher scheme participants.

- The finding of this study is that demand-side financing maternal healthcare voucher programs improved overall health status of the poor women.

Healthcare financing is massively related to the health status of the women for developing countries like Bangladesh. ${ }^{6}$ The Government of Bangladesh piloted a DSF scheme in 21 upazilas (sub-districts) from 2006 and expanded to 33 upazilas in 2007 where poor women receive a package of essential maternal health care services with the treatment of pregnancy and delivery related complications. ${ }^{7}$ After getting better

Correspondence: Akkur Chandra Das, Master(s) of Population Sciences (MPS) Scholar, Department of Population Sciences, University of Dhaka, Dhaka - 1000, Bangladesh. Email: akkurdas@gmail.com. 
results, this program has been expanded to another 11 upazilas in 2010 where increasing the demand for maternal health services was one of the principal objectives of the pilot program. After all, in health sector, DSF has a possible role in the delivery of certain sub-optimally and inequitably consumed services such as maternal care and betterment of unmet health behaviors. ${ }^{4}$ Then maternal mortality remains a major challenge to health systems worldwide and global initiatives to intensify policy intervention for maternal mortality began with the safe Motherhood Initiative in 1987. ${ }^{8}$ But it is not properly distributed among those who basically needed the financial assistance in their maternal period for antenatal, postnatal and delivery services. The services are limited and, as a result, maternal and infant mortality are still high in Bangladesh. On the other hand, the primary barriers to delivering in a health facility operate at the financial and family levels e.g. poor women have a clear preference for maternal health services from the private sector, which are perceived to be of higher quality, but cannot afford to pay for delivery care, and husbands or mother-in-laws often do not support delivery in a health facility. ${ }^{9}$

Voucher programs where it is either heavily subsidized or free for the patient, and the provider is reimbursed for the cost of service provision plus a reasonable profit after service delivery has been verified. ${ }^{10}$ Even well-funded maternal health projects have failed to increase skilled birth attendance among the poorest women. ${ }^{11}$ Progress in the decline of maternal mortality has been disappointingly slow in Pakistan even with the voucher scheme. ${ }^{9,12}$ However, In the Yunnan Province of China, it was found that voucher distribution has increased the utilization of treatment for childhood diarrhea among the poor. ${ }^{13}$ The voucher scheme was introduced for low-income pregnant women to enhance the utilization of maternal and child health services where this scheme covered the cost of antenatal care (ANC), delivery and postnatal care (PNC) as well as care of sick children. On the other hand, voucher schemes could be an option in India for increasing the utilization of reproductive and child health services if the vouchers were distributed properly among the poorest women. ${ }^{14}$ The scheme would play a significant role in the health sector of any country where the voucher mechanisms are used with a specific DSF mechanism which can be used to target essential health services to vulnerable populations, such as poor and pregnant women, in order to protect them from catastrophic expenditures such as emergency obstetric care $^{15}$ The importance of DSF primarily lies on its scope to integrate various human development approaches and advanced individual and societal capabilities. Under DSF, overall human development occurs as it addresses populations' social, environmental and economic risks or vulnerabilities ${ }^{9}$ so that voucher programs are intended to reduce financial barriers, increase choice for clients, increase efficiency in delivery and quality of services which will improve maternal health care. ${ }^{16}$ On the contrary, voucher schemes increased deliveries in health centers and improved antenatal and postnatal care to a lesser extent. However, schemes that targeted poorer women did not appear to be efficient since these women were more likely than less poor women to be encouraged to give birth in a public health-care facility, even with universal voucher schemes. ${ }^{17}$

The aim of the present study was to investigate the effect of voucher schemes on safe delivery and delivery care services among poor women at Bhola district in Bangladesh. The study also examines the effect of the voucher scheme on maternal health care in relation to the non-voucher scheme receivers.

\section{Materials and Methods}

A cross-sectional study was conducted from November 2014 to March, 2015 in seven Upazilas of Bhola District; they are Bhola Sadar Upazila, Burhanuddin Upazila, Charfasson Upazila, Daulatkhan Upazila, Lalmohan Upazila, Monpura Upazila, Tazumuddin Upazila among the 300 married women (age group 1549 years) who were pregnant or had at least a child. The respondents of the study were selected randomly among voucher scheme receivers or non-voucher scheme receivers.

A structured and pre-tested questionnaire with some open-ended questions was used to conduct face to face interviews. The questionnaire included the following information: age, parity, religion, educational status, socioeconomic status of households including household expenditures, and use of health services during the last pregnancy. Then data was analyzed using the Statistical Package for Social Science (SPSS), version 16.0. A descriptive analysis was done to analyze the socio-demographic characteristics of respondents, and bivariate analysis using the Pearson Chi-Square test was used to determine the associations with each of the outcome variables to finalize the study results. Written permission was taken from the Department of Population Sciences, University of Dhaka, Bangladesh for this study.

\section{Results}

Among the 300 respondents, 53 (17.7\%) were voucher scheme receivers and 247 (82.3) respondents were nonvoucher scheme receivers. The majority $(69.7 \%)$ of the respondents were in the $18-25$ years age group, $4 \%$ were less than 18 years, and $26.3 \%$ of the respondents were above 25 years old. More than half of the respondents $(53.7 \%)$ had primary level education, 30\% secondary, $9.3 \%$ higher secondary and $7 \%$ had no formal education. Most of the respondents (98\%) were housewives, and rest were involved in agriculture. Eighty seven percent of the respondents' income level was in the Tk. $0-1000$ category but only $13 \%$ of respondents' income was in the Tk. 1001-2000 category. Most of the respondents (94\%) were Muslim and rest were Hindu. Among the respondents, $22.3 \%$ had no children, $51 \%$ had 1 child, $19.4 \%$ had 2 children and $7.3 \%$ had 3 children.

It was also revealed that $14 \%$ of the respondents had a normal delivery, $5.3 \%$ needed a caesarean delivery, 
$65.4 \%$ required assisted vaginal delivery and $15.3 \%$ were pregnant at the time of study. It was also found that voucher scheme providers visited $50 \%$, counseled $9 \%$ and advised $41 \%$ of the voucher scheme receivers.

Table 1 shows the cross tabulation between delivery care services and the voucher scheme. A majority of the voucher scheme receivers received skilled birth attendance $(64.2 \%)$, institutional delivery services (86.9\%), transport costs $(92.5 \%)$ and referral to a doctor or expert $(86.9 \%)$. On the contrary, the figures for nonvoucher scheme receivers were lower for skilled birth attendance $(26.3 \%)$, institutional delivery services (24.7\%), transport costs $(23.1 \%)$ and referral to a doctor or expert $(22.3 \%)$.

The Odds Ratio (OR) of delivery care services and voucher scheme is: $50 \times 127 / 120 \times 3=17.64$. As the OR $>1$, it is suggested that respondents who are receiving the voucher scheme have 17.64 times higher odds of receiving delivery care services than the respondents who do not receive the voucher scheme and delivery care score (Table 2).

\section{Discussion}

In this study, it has found that voucher scheme receivers received better delivery care services which improved the maternal and child health. It was also observed that voucher scheme receivers received visit, counsel and advice by the voucher scheme providers. A study conducted in Bangladesh found that voucher programs were intended to reduce financial barriers, increase choice for clients, enhance efficiency in delivery and quality of services which would improve the maternal health care. ${ }^{16}$ Another study in Mexico found that families are encouraged to obtain preventive health care, participate in growth monitoring and nutrition supplements programs and attend health education programs to be eligible for cash transfer. ${ }^{18}$ The study findings suggest that the cash transfer component was associated with better outcomes in child health, growth and development. However, a study in Pakistan noted that well-funded maternal health projects failed to increase skilled birth attendance among the poorest women ${ }^{11}$ and progress of lowering the maternal mortality was disappointingly slow., ${ }^{9,2}$

Our study found that skilled birth attendance was provided to $62.4 \%$ voucher scheme receivers. A study found that there was a lower number of women who delivered with the help of skilled birth attendants. ${ }^{19}$ We also found that voucher scheme receivers had more institutional deliveries, received a larger proportion of their transport cost, and had more referrals to a doctor or expert in comparison to nonvoucher scheme receivers. It was noticed that there is considerable potential for improvement among the voucher scheme receivers groups in $2014 .{ }^{5}$ Financial protection is needed for the poorest to encourage the use of facilities for delivery and to prevent families from impoverishment. ${ }^{3}$

The present study also found that voucher scheme receivers are 17.64 times more likely to receive delivery care services than respondents who did not receive the voucher scheme. The voucher scheme lessens the number of maternal mortalities occurring due to complications during delivery. ${ }^{8}$ It is highlighted that the voucher scheme plays a significant role in reducing the maternal and neonatal morbidity, and mortality rate anywhere in the world. ${ }^{20}$

The time constraint was one of the major limitations of this study. Long-term follow-ups could have

Table 1: Delivery care services and voucher scheme

\begin{tabular}{|c|c|c|c|}
\hline \multirow{2}{*}{ Variables } & \multicolumn{2}{|c|}{ Voucher Scheme } & \multirow{2}{*}{$\begin{array}{c}\chi^{2} \text { and } \\
\text {-Value }\end{array}$} \\
\cline { 2 - 3 } & Yes & No & \multirow{2}{*}{$\chi^{2}=28.252$} \\
$p<0.000$
\end{tabular}

Table 2: Delivery care score and voucher scheme cross tabulation

\begin{tabular}{|c|c|c|c|}
\hline Variables & \multicolumn{2}{|c|}{ Voucher Scheme } & \multirow{2}{*}{$\begin{array}{c}\text { Pearson Chi-Square } \\
\boldsymbol{p} \text {-value }\end{array}$} \\
\cline { 2 - 3 } & Yes & No & \multirow{2}{*}{$p<0.000$} \\
\hline Delivery Care Score & & $120(48.6 \%)$ & \\
\hline High & $50(94.3 \%)$ & $127(51.4 \%)$ & \\
\hline Delivery Care Score & $3(5.7 \%)$ & $247(100 \%)$ & \\
\hline Lotal N (\%) & $53(100 \%)$ & & \\
\hline
\end{tabular}

South East Asia Journal of Public Health 2015;5(1):39-43 
provided more accurate findings. There were many sensitive personal/family issues which respondents might not have disclosed intentionally due to cultural and religious beliefs. This might have affected the outcome of the study leading to some bias in the result. The participants sometimes left the interview in the middle of their interview because of the their personal/ family problems and were not available for further interview.

\section{Conclusion and recommendations}

The study found that voucher scheme participants received more support during their delivery period than non-voucher scheme receivers and got the chance of improved access to safe delivery. Voucher scheme participants were advised, counseled and facilitated to reduce barriers to a safe delivery and utilization of health care services. The maternal health voucher scheme was found to remove many barriers so that poor women receive the maternal healthcare services they require for a safe delivery. Skilled birth attendance, institutional delivery services and transport costs received by voucher scheme participants were higher than non-voucher scheme receivers, and their health and delivery conditions were better, leading to fewer delivery complications.

To reduce maternal and infant mortality in Bangladesh, there must be a need to increase resource allocation in the health sector and proper utilization of both local and foreign resources with highlighting infrastructure development in the form of institutions, clinics, hospitals, research centers etc. Career opportunities in the health sector should be increased by offering motivation and incentives for skilled doctors and community health workers, nurses etc. Voucher scheme programs should be implemented by the government and non-government organizations throughout the country to ensure better quality maternal and child health services.

\section{References}

1. Keya KT, Rahman MM, Rob U, Bellows B. Distance travelled and cost of transport for use of facility-based maternity services in rural Bangladesh: a cross-sectional survey. Lancet 2013;382:17.

2. Van Doorslaer EV, O’Donnell O, Rannan-Eliya RP, Somanathan A, Adhikari SR, Garg CC, et al. Catastrophic payments for health care in Asia. Health Econ 2007;16(11):1159-84.

3. Hoque ME, Powell-Jackson T, Dasgupta SK, Chowdhury ME, Koblinsky M. Costs of Maternal Health-related Complications in Bangladesh. J Health Popul Nutr 2012;30 (2):205-12

4. Gopalan SS, Varatharajan D. Addressing maternal healthcare through demand side financial incentives: experience of Janani Suraksha Yojana program in India. BMC Health
Serv Res.2012;12(1): 319

5. Van de PoelE, Flores G, Ir P, O’Donnell O, Van Doorslaer E. Can vouchers deliver? An evaluation of subsidies for maternal health care in Cambodia. Bull World Health Organ 2014;92 (5):331-9.

6. WHO. Evaluating the quality of care for severe pregnancy complications: the WHO near-miss approach for maternal health. Geneva: World Health Organization, 2011.

7. Koehlmoos TLP, Ashraf A, Kabir H, Islam Z, Gazi R, Saha NC, et al. Rapid assessment of demand-side financing experiences in Bangladesh. Dhaka: International Centre for Diarrhoeal Disease Research, Bangladesh (ICDDR, B), 2008 .

8. Hogan MC, Foreman KJ, Naghavi M, Ahn SY, Wang M, Makela SM, et al. Maternal mortality for 181 countries, 1980-2008: a systematic analysis of progress towards Millennium Development Goal 5. Lancet 2010;375(9726):1609-23.

9. Agha S, Carton TW. Determinants of institutional delivery in rural Jhang, Pakistan. Int $J$ Equity Health 2011;10(1): 31

10. Bellows BW, Conlon CM, Higgs ES, Townsend JW, Nahed MG, Cavanaugh K et al. A taxonomy and results from a comprehensive review of 28 maternal health voucher programmes. $J$ Health Popul Nutr 2013;31.(4 Suppl 2): S106.

11. Mahmood A. Improving Maternal and Neonatal Health: Measuring the Impact of the PAIMAN Project in Ten Districts in Pakistan: Comparing Baseline and Endline Household Survey Findings (2005-2010). PAIMAN Project, 2010.

12. Midhet F, Becker S. Impact of community-based interventions on maternal and neonatal health indicators: Results from a community randomized trial in rural Balochistan, Pakistan. Reprod Health 2010;7(1): 1-31

13. Kelin D, Zhang K, Tang S. A draft report on a MCHPAF study in China. Washington: World Bank, 2001.

14. Bhatia MR, Yesudian CAK, Gorter A, Thankappan KR. Demand side financing for reproductive and child health services in India. Econ Polit Wkly 2006;279-84.

15. Ahmed S, Khan MM. A maternal health voucher scheme: what have we learned from the demand-side financing scheme in Bangladesh? Health Policy Plan 2010;26(1):25-32.

16. Rob U, Rahman M, Bellows B. Evaluation of the impact of the voucher and accreditation approach on improving reproductive behaviors and RH status: Bangladesh. BMC Public Health 2011;11 (1): 257. 
17. CDP. Implementing the Millennium Development Goals: Health Inequality and the Role of Global Health Partnership. New York: Committee for Development Policy, 2009.

18. Fernald LC, Gertler PJ, Neufeld LM. Role of cash in conditional cash transfer programmes for child health, growth, and development: an analysis of Mexico's Oportunidades. Lancet 2008;371(9615):828-37.
19. Hussein J, Bell J, Nazzar A, Abbey M, Adjei S, Graham W. The Skilled Attendance Index: Proposal for a New Measure of Skilled Attendance at Delivery. Reprod Health Matters 2004;12(24):160-70.

20. Onasoga OA, Afolayan JA, Oladimeij BD Factors Influencing Utilization of Antenatal Care Services among Pregnant Women in Ife Central Lga, Osun State, Nigeria. Adv Appl Sci Res 2012;3(3) :1309-15. 